\title{
ORIGEN PROBABLE Y TRANSMISIÓN ENTRE ESPECIES DEL SARS-CoV-2
}

\section{PROBABLE ORIGIN AND CROSS-SPECIES TRANSMISSION OF SARS-CoV-2}

Johanna Alvarado-Ortiz ${ }^{1}$, Lorena Meneses O. ${ }^{2}$ \& Fabio Idrovo-Espín ${ }^{1 *}$

Recibido: 17 de marzo 2020 / Aceptado: 6 de abril 2020 /

Publicado en linea: 8 de abril de 2020

DOI: $10.26807 / \mathrm{ia} . v 8 \mathrm{i} 2.142$

Palabras claves: Coronavirus, transmisión entre especies, secuencias.

Keywords: Coronavirus, cross-species transmission, sequences.

\section{RESUMEN}

A finales del año pasado se reportaron casos de pacientes con neumonía atípica en Wuhan, Provincia de Hubei, China. La mayoría de pacientes iniciales trabajaban, vivían o eran consumidores de productos del mercado mayorista de mariscos, lo que sugirió un posible contagio de un patógeno de origen animal al ser humano. Posteriormente, se determinó que el responsable fue un coronavirus, que se Ilamó SARS-CoV-2, cuya rápida propagación produjo la pandemia de la enfermedad coronavirus disease 19 (COVID-19). La enfermedad es actualmente motivo de preocupación e intensa investigación a nivel mundial.

1 Universidad Central del Ecuador, Facultad de Ciencias Químicas, Quito Ecuador (jaalvarado@uce. edu.ec, *correspondencia: fmidrovo@uce.edu.ec)

2 Pontificia Universidad Católica del Ecuador, Facultad de Ciencias Exactas y Naturales, Escuela de Ciencias Químicas, Quito Ecuador (Immeneses@puce.edu.ec) 
Se han postulado teorías sobre el origen del coronavirus, siendo la más aceptada que el virus proviene del pangolín malayo. Con la finalidad de reforzar esta teoría, en la presente investigación, a partir de secuencias nucleotídicas de dominio público, se seleccionaron fragmentos de secuencias nucleotídicas que codifican para la espícula glicoprotéica superficial de coronavirus en algunos organismos hospederos infectados por diferentes cepas de coronavirus incluyendo el SARS-CoV-2. De la filogenia y análisis de secuencias de amino ácidos de la espícula glicoprotéica del coronavirus se encontró posibles eventos de transmisión entre especies del virus responsable de la enfermedad incluyendo el ser humano.

\section{ABSTRACT}

At the end of last year, were reported cases of patients with atypical pneumonia in Wuhan, Hubei Province, China. Most of the initial patients worked, lived or were consumers of products from the wholesale seafood market, which suggested a possible transmission of a pathogen of animal origin to humans. Later, it was determined that the culprit was a coronavirus, named SARS-CoV-2, whose rapid spread caused the pandemic of coronavirus disease 19 (COVID19). The disease is currently a cause for concern and intense research worldwide. Theories on the origin of the coronavirus have been postulated, being the most widely accepted that the virus comes from the Malay pangolin. With the intention of reinforce this theory, in this research, from nucleotide sequences in the public domain, were selected Fragments of nucleotide sequences encoding the coronavirus surface spike glycoprotein from some host organisms infected by different coronavirus strains including SARS-CoV-2. From phylogeny and acid amino acid sequence analysis were found possible cross-species transmission of the virus responsible of the disease including humans. 


\section{INTRODUCCIÓN}

La aparición de un nuevo virus tiende a afectar de forma local a la población. La propagación, dependiendo de las características del virus, puede en cambio repercutir a nivel mundial afectando la economía, el sistema de salubridad de los países involucrados y el estado de ánimo de la población. A lo largo de la historia de la humanidad, esta se ha enfrentado a múltiples epidemias que han causado grandes pérdidas de vidas humanas y colapsado la economía mundial (Tabla 1).

Tabla 1. Principales epidemias virales y bacterianas de la historia

\begin{tabular}{|c|c|c|}
\hline Nombre & Características & Referencia \\
\hline $\begin{array}{l}\text { Peste antonina o } \\
\text { plaga de Galeno }\end{array}$ & $\begin{array}{l}\text { Viral, probablemente viruela. Originaria de Meso- } \\
\text { potamia, distribuida en el Imperio Romano entre } \\
\text { el } 164 \text { al } 182 \text { d.C. Entre medio millón a un millón } \\
\text { de fallecidos }\end{array}$ & $\begin{array}{l}\text { Sabbatani, y Fiorino } \\
\text { (2009) }\end{array}$ \\
\hline Plaga de Justiniano & $\begin{array}{l}\text { Bacteriana (Yersinia pestis). Considerada como } \\
\text { "La primera pandemia"; sin embargo, se expandió } \\
\text { en el Mediterráneo y Europa entre el. } 541 \text { y } 750 \\
\text { d.C. La cifra de fallecidos no está bien definida. }\end{array}$ & $\begin{array}{l}\text { Mordechai, Eisenberg, } \\
\text { Newfield, Izdebski } \\
\text { y Poinar (2019) }\end{array}$ \\
\hline Muerte negra & $\begin{array}{l}\text { Bacteriana (Yersinia pestis). Originaria de Asia } \\
\text { central se dispersó en el Medio Oriente y el norte } \\
\text { de África entre } 1347 \text { y } 1351 \text {. Los fallecidos fueron } \\
\text { entre el } 30 \text { y } 50 \% \text { de la población total. }\end{array}$ & $\begin{array}{l}\text { Monecke, Monecke } \\
\text { y Monecke, (2009); } \\
\text { Dewitte, (2010) }\end{array}$ \\
\hline Gripe rusa & $\begin{array}{l}\text { Viral. Se dispersó por vía terrestre y marítima a tra- } \\
\text { vés de Europa y luego a América del Norte entre } \\
1889 \text { y } 1890 \text {. Alrededor de un millón de fallecidos. }\end{array}$ & $\begin{array}{l}\text { Saunders-Hastings } \\
\text { y Krewski, (2016) }\end{array}$ \\
\hline Gripe española & $\begin{array}{l}\text { Viral. Mundial. Entre } 1918 \text { y 1919. Alrededor de } 50 \\
\text { millones de fallecidos. }\end{array}$ & $\begin{array}{l}\text { Martini, Gazzaniga, Bra- } \\
\text { gazzi y Barberis, (2019) }\end{array}$ \\
\hline Sida & $\begin{array}{l}\text { Viral. Mundial. Originaria del África. El subtipo B es } \\
\text { probablemente originario del Caribe (1967) para } \\
\text { posteriormente transmitirse a Estados Unidos en } \\
\text { los primeros años de la década de los } 70 \text {. Alrede- } \\
\text { dor de } 32 \text { millones de fallecidos desde el inicio de } \\
\text { la pandemia. }\end{array}$ & $\begin{array}{l}\text { Worobey et al., (2016); } \\
\text { GHO, (2020) }\end{array}$ \\
\hline $\begin{array}{l}\text { SARS (Severe } \\
\text { acute respiratory } \\
\text { syndrome) }\end{array}$ & $\begin{array}{l}\text { Viral. Contagios en } 30 \text { países. El brote inició en la } \\
\text { Provincia de Guangdong en China. De origen } \\
\text { animal, } 774 \text { fallecidos entre } 2002 \text { y } 2003 \text {. }\end{array}$ & $\begin{array}{l}\text { Vijayanand, Wilkins, } \\
\text { y Woodhead, (2004) }\end{array}$ \\
\hline $\mathrm{HINI}$ & $\begin{array}{l}\text { Viral. Aviar, de origen Euroasiático. El brote origi- } \\
\text { nado en México es una nueva cepa encontrada } \\
\text { en cerdos. Afectó a América del Norte y Central, } \\
\text { Europa y algunos países asiáticos en el } 2009 \text { con } \\
\text { un saldo de } 20 \text { fallecidos. }\end{array}$ & Mena et al., (2016) \\
\hline
\end{tabular}


La propagación de un patógeno animal a un humano, se conoce como transmisión entre especies o "spillo$v e r$. Este es un proceso complejo no comprendido del todo, que involucran muchos factores, ambientales, geográficos, sanitarios etc. (Plowright et al., 2017). Los virus son responsables directos de enfermedades en mamíferos entre ellos se encuentran los coronavirus. Estos forman parte de una familia cuyo genoma está compuesto por RNA monocatenario positivo. Se encuentran distribuidos en todo el mundo y son altamente infecciosos por naturaleza, causan enfermedades entéricas, respiratorias y en algunos casos neurológicas en una amplia variedad de animales y en humanos (Lai y Holmes, 2001; Gorbalenya et al., 2020). Entre los coronavirus de origen animal que se transmitieron al ser humano y provocaron epidemias se incluye el de Síndrome Respiratorio Agudo Severo (SARS-CoV), el coronavirus del Síndrome Respiratorio del Medio Oriente (MERS-CoV) y el recientemente identificado SARS-CoV-2 (Huang et al., 2020).

En los últimos días de diciembre de 2019, se detectó alrededor de 99 casos atípicos de neumonía en la ciudad Wuhan, provincia de Hubei en China; 49 de estos casos se relacionaron con el mercado mayorista de mariscos de Huanan entre consumidores, habitantes y trabajadores del mercado (Chen et al., 2020). Los casos siguieron aumentando y se emitió una alerta a los sistemas sanitarios del país asiático. Para el primero de enero del presente año, se descubrió el foco inicial del virus en el mercado de Huanan, lugar donde se vendía pescado y animales silvestres vivos como aves de corral, murciélagos, marmotas y serpientes ( $\mathrm{Lu}$, Stratton y Tang, 2020; Wu y McGoogan, 2020). En ese mismo mes, un grupo de científicos chinos secuenciaron el genoma del "Aislado del virus de la neumonía del mercado de mariscos de Wuhan (Wuhan-Hu-1)". El grupo identificó que el virus era un coronavirus y reportó la secuencia de nucleótidos en la base de datos del NCBI (1988) con el número de accesión NC_045512.2.

El SARS-CoV-2 comenzó a propagarse de forma descontrolada. A mediados de enero se registró el primer caso fuera de China, se aisló la ciudad de Wuhan y posteriormente 15 
ciudades chinas más. La curva epidémica tuvo un crecimiento muy elevado y la enfermedad presentó una tasa de mortalidad del 2,3\%. Para el 30 de enero del 2020 la Organización Mundial de la Salud (WHO, por sus siglas en inglés) catalogó al SARSCoV-2 como una "emergencia de salud pública de preocupación internacional" (Wu y McGoogan, 2020) y para el 11 de marzo, declaró la pandemia de COVID-19. Desde esa fecha el número de contagios progresó de forma sostenida a nivel mundial (Figura 1). La información sobre personas contagiadas, recuperadas y fallecidas en todo el mundo se actualizó en bases de datos públicas todos los días en tiempo real (Gardner, 2020; WHO, 2020).

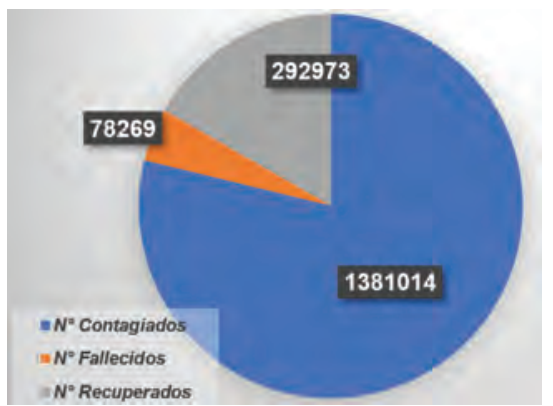

Figura 1. Número de personas afectadas por la infección de COVID-19 en 184 de 194 países totales

(Basada en WHO, 2020)

El primer caso en el Ecuador se registró el 29 de febrero y se inició el crecimiento exponencial de contagiados en función del tiempo (Figura 2), convirtiéndose desde entonces en un problema de salud pública sumamente serio en nuestro país.

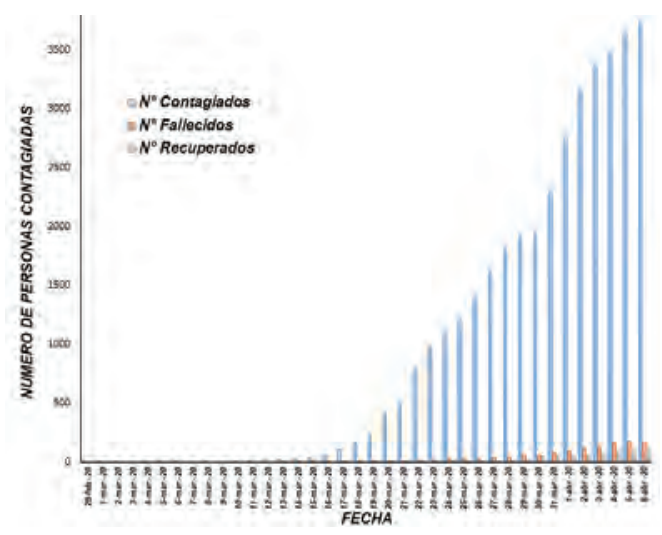

Figura 2. Número de personas afectadas por la infección de COVID-19 en el Ecuador (Basada en WHO, 2020) 
De acuerdo con Newman et al., (2006) los viriones o partículas virales (unidad estructural de los virus con capacidad de infección) del coronavirus son esféricos con un diámetro aproximado de $125 \eta \mathrm{m}$. En la superficie del virión se encuentra una estructura trimérica denominada espí- cula glicoprotéica (Figura 3), esta es necesaria para la replicación del coronavirus ya que se une a receptores celulares de superficie de las células hospederas. El rango de hospederos del coronavirus depende de la afinidad entre ellos.

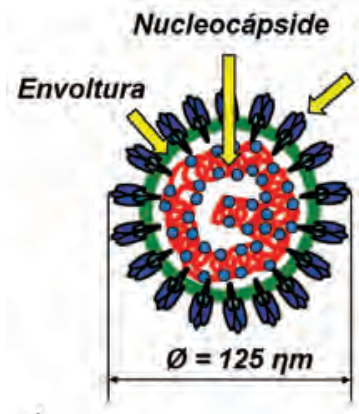

a)

Figura 3. Estructura básica del coronavirus

a) virión $n$-Cov b) espícula glicoprotéica

(Basada en Newman et al., 2006; Belouzard, Millet, Licitra, y Whittaker, 2012)

De acuerdo con Song, Gui, Wang y Xiang, (2018), algunos coronavirus se unen a la enzima convertidora de angiotensina 2 del receptor celular (ACE2) y media la fusión de las membranas del coronavirus y la célula promoviendo el ingreso del virus por endocitosis para posteriormente liberar la nucleocápside viral dentro del citoplasma de la célula e iniciar la replicación del virus (Figura 4).
Adicionalmente a los estudios de la función, estructura de la espícula glicoprotéica y sus reordenamientos conformacionales para promover la entrada del virus (Song, Gui, Wang y Xiang, 2018) también se encuentran disponibles las secuencias de nucleótidos que codifican para las espículas glicoprotéicas de coronavirus en diferentes especies (Kan et al., 2005; Hu et al., 2017; Liu et al., 2019). 


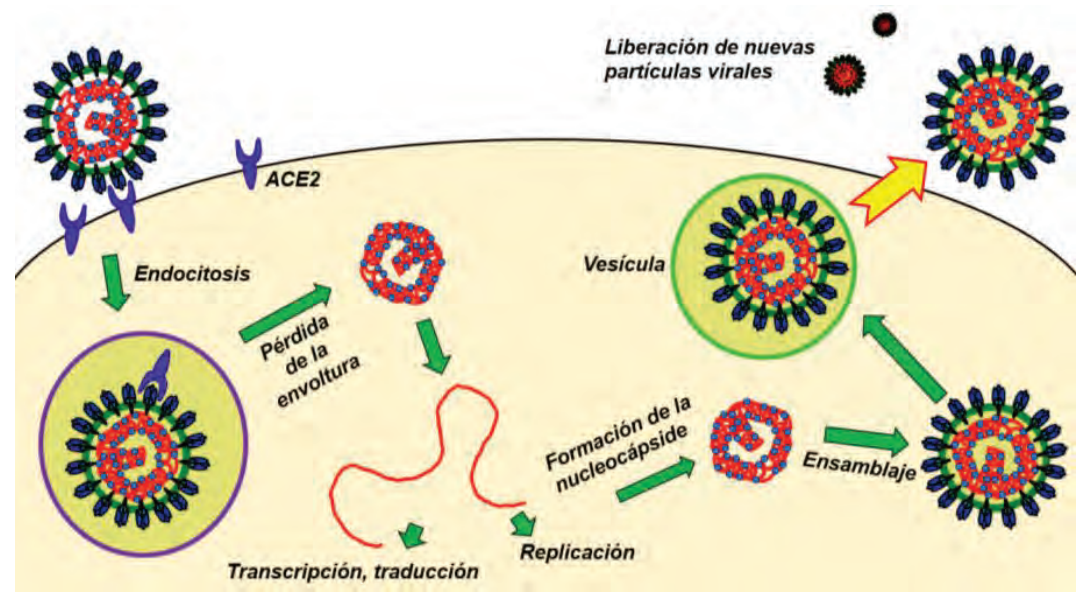

Figura 4. Mecanismo de replicación del coronavirus

(Basada en Belouzard, Millet, Licitra y Whittaker, 2012;

Song, Gui, Wang y Xiang, 2018)

De lo antes expuesto, con la información genómica disponible, en el presente estudio, se plantea definir el ori gen más probable del SARS-CoV-2 y así contribuir a fortalecer el conocimiento sobre este nuevo virus y las enfermedades derivadas del mismo

\section{MATERIALES Y MÉTODOS}

Considerando el gen que codifica para la espícula glicoprotéica de coronavirus, se utilizó fragmentos (48 pb de longitud) de 32 secuencias corespondientes a cepas reportadas por Kan et al., (2005), un fragmento de la secuencia viral del murciélago rufo de herradura (Rhinolophus sini- cus) con número de accesión MG772933.1 descrita por Hu et al., (2018) y un fragmento homólogo a partir del genoma de SARS-CoV-2 (Sequence ID: NC_045512.2) responsable del COVID-19. Con la secuencia AY687357 se realizó una búsqueda mediante blast (Basic Local 
Alignment Search Tool referido por Altschul, Gish, Miller, Myers y Lipman, 1990) de nucleótidos contra las secuencias de pangolín malayo (Ma nis javanica) del proyecto PRJNA57 3298 (Liu, Chen y Chen (2019). De las secuencias resultantes del blast se seleccionaron aquellas que presentaron porcentajes de identidad cercanos al $100 \%$, se depuró las secuencias y se trabajó finalmente con aquellas que fueron homólogas al fragmento de $48 \mathrm{pb}$.

Con las secuencias se realizó un alineamiento, un modelo y se obtuvo el árbol filogenético mediante MEGAX. 10.1.7 (Kumar, Stecher, Li, Knyaz y Tamura, 2018). Se utilizó la secuencia At1g24610 como outgroup.

La traducción a proteína de las secuencias genómicas se realizó mediante la plataforma ExPASy (Gastei ger et al., 2003) y se verificó que correspondieran a la espícula glicoprotéica mediante blastp (Altschul et al., 1990). Para visualizar la composición de aminoácidos (aa) en las secuencias de cada clado y subclado se generaron figuras tipo logo mediante WebLogo (Crooks et al., 2004).

\section{RESULTADOS}

Del genoma NC_045512.2, se determinó que la secuencia de nucleótidos AAAAAGAGTTGATTTTTGTGG AAAGGGCTATCATCTTATGTCCTT CCC codifica para la espícula glicoprotéica del SARS-CoV-2 (identificada en este trabajo como $\mathrm{H}$. Sapiens SARS-CoV-2)

De las secuencias de pangolín malayo, 122 presentaron porcentajes de identidad adecuados y de estas 37 fueron homólogas y tenían la misma longitud que el fragmento referido en la publicación de Kan et al., (2005).

Mediante la información genómica disponible se elaboró un alineamiento con 71 secuencias (no se muestra este resultado) y un árbol filogenético por del método HKY con un bootstrap de 1000 y distribución gamma de 5. En el árbol (Figura 5) se observó dos grupos monofiléticos principales, el primero comprendido por la secuencia de pangolín malayo gnI| SRA 
|SRR10168377.9857580.2:2-150, referida como Sec1 en este estudio y un gran grupo monofilético con las 69 secuencias restantes.

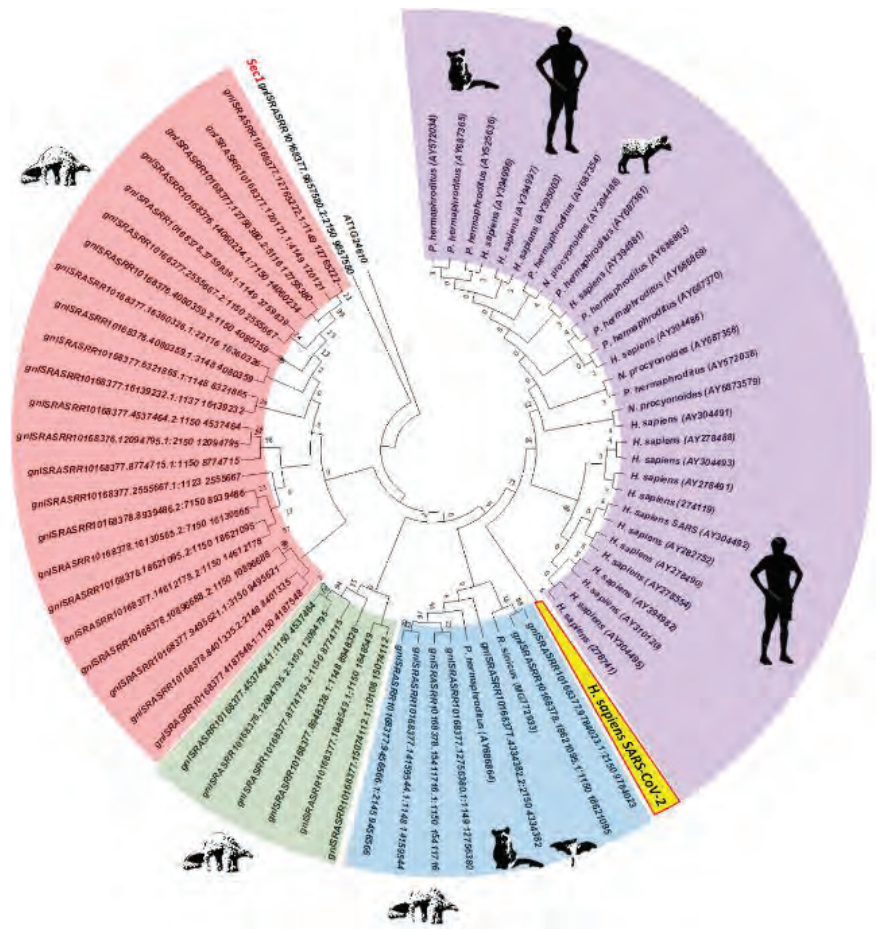

Figura 5. Árbol filogenético de secuencias genómicas que codifican para la espícula glicoprotéica de coronavirus en diferentes especies hospederas.

Las secuencias cuyos nombres empiezan con el prefijo gnISRASRR10168377 son de pangolín malayo y corresponden al proyecto PRJNA573298

(Liu, Chen y Chen 2019)

Dentro del grupo monofilético mayor, se observan un grupo comprendido por 23 (clado rojo) y otro grupo con las secuencias restantes (subclados verde, azul, amarillo y violeta). El clado rojo y el subclado verde se componen exclusivamente de secuencias de pangolín malayo, indicativo de que diferentes cepas de coronavirus circulaban dentro de individuos de esta especie. En el siguiente grupo monofilético se 
encuentra un clado con 40 secuencias, conformado a su vez por subclados (amarillo, azul y violeta). La disposición de las secuencias dentro del subclado azul indicaría 2 eventos de transmisión entre especies del virus por tanto de la enfermedad, el primero desde el pangolín malayo hacia el murciélago rufo de herradura y el segundo desde el pangolín malayo hacia la civeta de la palma asiática. El subclado amarillo, es una nueva bifurcación de la cual derivó la secuencia viral $\mathrm{H}$. sapiens SARSCoV-2 (responsable del COVID-19), es probable que esta cepa haya surgido antes que las cepas responsables de la epidemia de SARS (subclado violeta) cuyo origen fue la civeta de la palma asiática (Wang et al., 2005). Finalmente en el subclado violeta se encontró secuencias virales homólogas en la civeta de la palma asiática, mapache japonés y el ser humano lo que indicaría un nuevo evento de transmisión entre especies de la enfermedad.
Al realizar la traducción de cada secuencia de nucleótidos, que codifican para la espícula glicoprotéica de coronavirus se observó variaciones en cada clado y subclado que se resumen en una figura tipo logo (Figura 6). La secuencia Sec1 es la más divergente de todas, a partir de esta se observó la variación de los residuos de aminoácidos en cada posición (1 a 14). Siguiendo el sentido probable de la transmisión del coronavirus entre especies, las secuencias se vuelven menos divergentes conforme se establece en un grupo de especies en particular. Es así, que al Ilegar al subclado violeta la secuencia de la espícula glicoprotéica de diferentes cepas de coronavirus es exactamente la misma para el mapache japonés, la civeta de la palma asiática y el ser humano. Si bien la secuencia de nucleótidos que codifica para la espícula glicoprotéica del $\mathrm{H}$. sapiens SARS-CoV-2 (subclado amarillo) es diferente, es exactamente la misma a nivel de residuos de aminoácidos (Figura 6). 


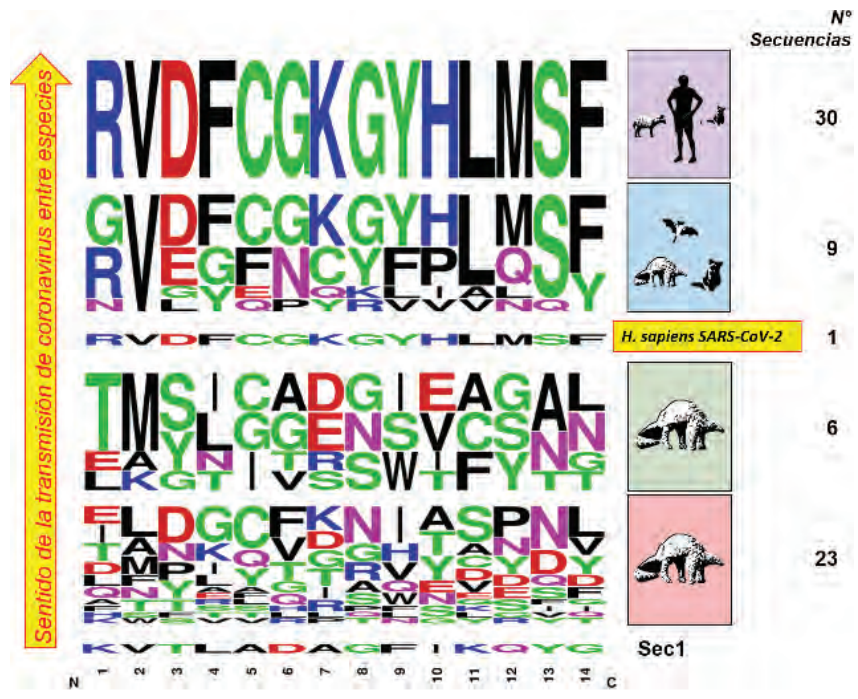

Figura 6. Logo de secuencias predichas de aa correspondientes a la espícula glicoprotéica de coronavirus en las especies estudiadas. Se indica el posible sentido de la transmisión de coronavirus. La secuencia predicha de aa para las secuencias de los subclados amarillo y violeta es la misma RVDFCGKGYHLMSF

\section{DISCUSIÓN}

De la filogenia obtenida en este estudio se observa que las cepas virales se desarrollaron inicialmente en pangolines malayos, las cuales fueron mutando y provocaron la transmisión del virus entre diferentes especies de mamíferos. Aun así, con este árbol filogenético no es posible aseverar que el pangolín malayo es el responsable directo de la transmisión del SARSCoV-2 al ser humano, ya que los árboles filogenéticos indican las rela- ciones evolutivas más probables entre secuencias (o especies). Adicionalmente, cualquier otro mamífero que se vendía en el mercado de Huanan pudo ser el reservorio viral de la cepa que se transfirió al ser humano. Al inicio de la epidemia se pensó que el origen más probable del SARSCoV-2 era la serpiente, al considerar la maquinaria traduccional de Bungarus multicinctusa y Naja atra y el sesgo en el uso de codones de estas 
dos especies (Ji, Wang, Zhao, Zai y Li 2020). Sin embargo, la evidencia posterior fue orientando al origen del virus en el pangolín malayo.

Además, existe la posibilidad de contagio con un mamífero que no esté en cautiverio. Los murciélagos son reservorios de coronavirus y su capacidad para volar les confiere la posibilidad de ocupar un amplio hábitat a nivel mundial y dispersar enfermedades (Woo et al., 2012; Hu et al., 2017, Tao et al., 2017; Luo et al., 2018).

Retomando nuevamente la filogenia, se observa que la secuencia viral $\mathrm{H}$. sapiens SARS-CoV-2 probablemente haya aparecido antes que las cepas de SARS de la epidemia del 2003 (subclado violeta) y la cepa de origen animal SARS-CoV-2 haya estado presente en algún mamífero hospedero como el mapache japonés o la civeta de la palma asiática (subclado azul) hasta que infectó a cualquiera de los 99 pacientes iniciales del COVID-19 reportados por Chen et al. (2020). De todo lo expuesto anteriormente, se aprecia que para entender la enfermedad y desarrollar posibles vacunas se requieren más ensayos, secuenciaciones y análisis genómico de cepas virales de hospederos infectados para poder elucidar completamente el camino mediante el cual el virus SARSCoV-2 infectó el ser humano.

Según Geoghegan y Holmes (2008), la evolución de la virulencia es un tema no resuelto aún y los estudios experimentales referidos a los determinantes de esta enfermedad, dentro de un marco filogenómico, contribuirán a la comprensión integral de su evolución. Es importante mencionar que las infecciones por SARS-CoV-2, se presentarán de forma recurrente. La enfermedad se volvió estacional y se espera que afecte con mayor intensidad en países templados de América del Norte (Neher et al., 2020); sin embargo, estos modelos pueden fallar al estimar el comportamiento de una epidemia y es probable que el Ecuador vuelva a presentar focos infecciosos en el futuro.

Debido al profundo impacto de esta pandemia la información genómica del SARS-CoV-2 se actualiza todos los días de forma vertiginosa y puede ser consultada libremente en bases de datos especializadas como el $\mathrm{NCBI}$ (NCBI Resource Coordinators, 2018) o ViPR (Pickett et al., 2012). Vigorosos esfuerzos se realizan a nivel mundial 
para contener al virus y buscar una posible cura.

Respecto a la traducción predicha de secuencias, es evidente que el código genético, al ser degenerado permite la codificación de un aa por más de un triplete; lo interesante en nuestro análisis es que las secuencias de nucleótidos que codifican para la espícula glicoprotéica del $\mathrm{H}$. sapiens SARS-CoV-2 y las del subclado violeta (encontrada en pacientes de la epidemia de SARS del 2003) son diferentes, pero, a nivel de la traducción proteica, son las mismas motivo por el cual el H. sapiens SARS-CoV2 consiguió infectar las células en el ser humano.

Recientemente Zhou et al., (2020) determinaron que las proteínas ACE2 humanas son los receptores celulares a través del cual ingresa el virus SARS-CoV-2, justo como ocurre con la cepa Urbani de SARS-CoV común en Asia (Li et al., 2003), este estudio coincide con nuestro resultado ya que las espículas glicoprotéicas (idénticas en la secuencia de aa predicha) ingresan a las células a través de los mismos receptores celulares.
De acuerdo a nuestros resultados, nuevamente ha quedado en evidencia el enorme riesgo de interactuar con especies silvestres que son reservorios virales. Las especies silvestres no deberían formar parte de la cadena alimenticia del ser humano ni destinarse a la domesticación, recreación o compañía.

Según el Centro para el Control y la Prevención de Enfermedades de Estados Unidos (CDC, 2013), la epidemia de SARS del 2003 se desarrolló en 29 países, contagió a 8096 con alrededor de 774 decesos. En esta ocasión enfrentamos una pandemia sumamente peligrosa, se debería endurecer la legislación a nivel local y mundial para regular estas actividades.

Debido a que existen costumbres arraigadas en diferentes culturas, al menos se deberían seguir las normativas internacionales como las de la OPS (2015), que especifican que los animales expendidos en mercados, destinados a la alimentación deben manejarse con prácticas de higiene análogas e igual de exigentes a las de un alimento procesado, con la finalidad de garantizar la inocuidad del 
producto final y proteger a los consumidores. Paralelamente se deben proseguir con las investigaciones referidas a virus de origen animal y la transmisión entre especies de acuer- do con las recomendaciones de $\mathrm{Hu}$ et al., (2018), Lu, Stratton y Tang (2020) y Zhou et al., (2020) entre otros.

\section{CONCLUSIÓN}

Existe evidencia que respalda el origen más probable del SARS-CoV-2 en el pangolín malayo, a partir de las secuencias nucleotídicas que codifican para la espícula glicoprotéica de este coronavirus.

Los ensayos que se están realizando a nivel mundial ayudarán a definir con mayor exactitud el origen y comportamiento del virus así como el eventual tratamiento de la enferme- dad en esta pandemia y en rebrotes.

Se requieren medidas legales drásticas para evitar la interacción con animales silvestres, posibles reservorios de virus infecciosos para el ser humano. Cuando los animales se destinan al consumo humano deben respetarse al menos las normativas de manejo de alimentos para garantizar la higiene e inocuidad de los mismos. 


\section{LISTA DE REFERENCIAS}

Altschul, S. F., Gish, W., Miller, W., Myers, E. W., \& Lipman, D. J. (1990). Basic local alignment search tool. Journal of molecular biology, 215(3), 403-410. https://doi.org/10.1016/S0022-2836(05)80360-2

Belouzard, S., Millet, J. K., Licitra, B. N., \& Whittaker, G. R. (2012). Mechanisms of coronavirus cell entry mediated by the viral spike protein. Viruses, 4(6), 1011-1033. https://doi.org/10.3390/v4061011

Centro para el Control y la Prevención de Enfermedades de Estados Unidos. (2013). CDC SARS Response Timeline. Recuperado de: https://www.cdc.gov/about/history/sars/timeline.htm

Chen, N., Zhou, M., Dong, X., Qu, J., Gong, F., Han, Y., Qiu, Y., Wang, J., Liu, Y., Wei, Y., Xia, J., Yu, T., Zhang, X., \& Zhang, L. (2020). Epidemiological and clinical characteristics of 99 cases of 2019 novel coronavirus pneumonia in Wuhan, China: a

Descriptive study. Lancet, 395(10223), 507-513. https://doi.org/10.1016/S01406736(20)30211-7

Crooks, G. E., Hon, G., Chandonia, J. M., \& Brenner, S. E. (2004). WebLogo: a sequence logo generator. Genome research, 14(6), 1188-1190. https://doi.org/10.1101 /gr.849004

Dewitte S. N. (2010). Age Patterns of Mortality During the Black Death in London, A.D. 1349-1350. Journal of archaeological science, 37(12), 3394-3400. https://doi.org/ 10.1016/j.jas.2010.08.006

Gardner, L. Mapping 2019-nCoV (2020). Recuperado de: https://coronavirus.jhu. edu/map.html (accedido el 04/04/2020).

Gasteiger, E., Gattiker, A., Hoogland, C., Ivanyi, I., Appel, R. D., \& Bairoch, A. (2003). ExPASy: The proteomics server for in-depth protein knowledge and analysis. Nucleic acids research, 31(13), 3784-3788. https://doi.org/10.1093/nar/gkg563 
Geoghegan, J. L., \& Holmes, E. C. (2018). "The phylogenomics of evolving virus virulence". Nature reviews. Genetics, 19(12), p. 756-769. https://doi.org/10.1038/ s41576-018-0055-5

Gorbalenya, A., Baker, S., Baric, R., de Groot, R., Drosten, C., ... Ziebuhr, J. (2020). The species Severe acute respiratory syndrome-related coronavirus: classifying 2019nCoV and naming it SARS-CoV-2. Nat Microbiol, 5, 536-544. https://doi.org/10. 1038/s41564-020-0695-Z

Huang, C., Wang, Y., Li, X., Ren, L., Zhao, J., Hu, Y., Zhang, L., Fan, G., Xu, J., Gu, X., Cheng, Z., Yu, T., Xia, J., Wei, Y., Wu, W., Xie, X., Yin, W., Li, H., Liu, M., Xiao, Y., ... Cao, B. (2020). Clinical features of patients infected with 2019 novel coronavirus in Wuhan, China. Lancet, 395(10223), 497-506. https://doi.org/10.1016/ S0140-6736(20)30183-5

GHO (2020). Global Health Observatory (CH), World Health Organization HIV/AIDS (Recuperado de: https://www.who.int/gho/hiv/en/ (accedido el 22/03/2020).

Hu, B., Zeng, L. P., Yang, X. L., Ge, X. Y., Zhang, W., Li, B., Xie, J. Z., Shen, X. R., Zhang, Y. Z., Wang, N., Luo, D. S., Zheng, X. S., Wang, M. N., Daszak, P., Wang, L. F., Cui, J., \& Shi, Z. L. (2017). Discovery of a rich gene pool of bat SARS-related coronaviruses provides new insights into the origin of SARS coronavirus. PLoS pathogens, 13(11), e1006698. https://doi.org/10.1371/journal.ppat.1006698

Hu, D., Zhu, C., Ai, L., He, T., Wang, Y., Ye, F., Yang, L., Ding, C., Zhu, X., Lv, R., Zhu, J., Hassan, B., Feng, Y., Tan, W., \& Wang, C. (2018). "Genomic characterization and infectivity of a novel SARS-like coronavirus in Chinese bats". Emerging microbes \& infections, 7(1), 154. https://doi.org/10.1038/s41426-018-0155-5

Ji, W., Wang, W., Zhao, X., Zai, J., \& Li, X. (2020). Cross-species transmission of the newly identified coronavirus 2019-nCoV. Journal of medical virology, 92(4), 433440. https://doi.org/10.1002/jmv.25682 
Kan, B., Wang, M., Jing, H., Xu, H., Jiang, X., Yan, M., Liang, W., Zheng, H., Wan, K., Liu, Q., Cui, B., Xu, Y., Zhang, E., Wang, H., Ye, J., Li, G., Li, M., Cui, Z., Qi, X., Chen, K., ... Xu, J. (2005). "Molecular evolution analysis and geographic investigation of severe acute respiratory syndrome coronavirus-like virus in palm civets at an animal market and on farms". Journal of virology, 79(18), p. 11892-11900. https://doi.org/10.1128/JVI.79.18.11892-11900.2005

Kumar, S., Stecher, G., Li, M., Knyaz, C., \& Tamura, K. (2018). "MEGA X: Molecular Evolutionary Genetics Analysis across Computing Platforms". Molecular biology and evolution, 35(6), pp. 1547-1549. https://doi.org/10.1093/molbev/msy096

Lai, M., y Holmes, K. (2001). "Coronaviridae: the viruses and their replication". En: Knipe, D. M. y Howley, P. M. (Eds.). Fields Virology (p. 1163-1185). .Philadelphia, EUA: Lippincott Williams \& Wilkins.

Li, W., Moore, M. J., Vasilieva, N., Sui, J., Wong, S. K., Berne, M. A., Somasundaran, M., Sullivan, J. L., Luzuriaga, K., Greenough, T. C., Choe, H., \& Farzan, M. (2003). Angiotensin-converting enzyme 2 is a functional receptor for the SARS coronavirus. Nature, 426(6965), 450-454. https://doi.org/10.1038/nature02145

Liu, P., Chen, W., y Chen, J. P. (2019). "Viral Metagenomics Revealed Sendai Virus and Coronavirus Infection of Malayan pangolin (Manis javanica)". Viruses, 11(11), 979. https://doi.org/10.3390/v11110979

Lu, H., Stratton, C. W., \& Tang, Y. W. (2020). Outbreak of pneumonia of unknown etiology in Wuhan, China: The mystery and the miracle. Journal of medical virology, 92(4), 401-402. https://doi.org/10.1002/jmv.25678

Luo, Y., Li, B., Jiang, R. D., Hu, B. J., Luo, D. S., Zhu, G. J., Hu, B., Liu, H. Z., Zhang, Y. Z., Yang, X. L., \& Shi, Z. L. (2018). Longitudinal Surveillance of Betacoronaviruses in Fruit Bats in Yunnan Province, China During 2009-2016. Virologica Sinica, 33(1), 87-95. https://doi.org/10.1007/s12250-018-0017-2

Martini, M., Gazzaniga, V., Bragazzi, N. L., \& Barberis, I. (2019). The Spanish Influenza Pandemic: a lesson from history 100 years after 1918. Journal of preventive medicine and hygiene, 60(1), E64-E67. https://doi.org/10.15167/2424248/jpmh 2019.60.1.1205 
Mena, I., Nelson, M. I., Quezada-Monroy, F., Dutta, J., Cortes-Fernández, R., LaraPuente, J. H., Castro-Peralta, F., Cunha, L. F., Trovão, N. S., Lozano-Dubernard, B., Rambaut, A., van Bakel, H., \& García-Sastre, A. (2016). Origins of the 2009 H1N1 influenza pandemic in swine in Mexico. eLife, 5, e16777. https://doi.org/ 10.7554/eLife. 16777

Mordechai, L., Eisenberg, M., Newfield, T. P., Izdebski, A., Kay, J. E., \& Poinar, H. (2019). The Justinianic Plague: An inconsequential pandemic?. Proceedings of the National Academy of Sciences of the United States of America, 116(51), 25546-25554. https://doi.org/10.1073/pnas.1903797116

Monecke, S., Monecke, H., \& Monecke, J. (2009). Modelling the black death. A historical case study and implications for the epidemiology of bubonic plague. International journal of medical microbiology, 299(8), 582-593. https://doi.org/10.1016 /j.ijmm.2009.05.003

NCBI Resource Coordinators (2018). "Database resources of the National Center for Biotechnology Information". Nucleic acids research, 46(D1), D8-D13. https:// doi.org/10.1093/nar/gkx1095

NCBI. (1988). National Library of Medicine (US), National Center for Biotechnology Information Recuperado de: https:/www.ncbi.nlm.nih.gov/nuccore/NC_045512.2 (accedido el 27/02/2020).

Neuman, B. W., Adair, B. D., Yoshioka, C., Quispe, J. D., Orca, G., Kuhn, P., Milligan, R. A., Yeager, M., \& Buchmeier, M. J. (2006). Supramolecular architecture of severe acute respiratory syndrome coronavirus revealed by electron cryomicroscopy. Journal of virology, 80(16), p. 7918-7928. https://doi.org/10.1128/JVI.00645-06

Neher, R. A., Dyrdak, R., Druelle, V., Hodcroft, E. B., \& Albert, J. (2020). Potential impact of seasonal forcing on a SARS-CoV-2 pandemic. Swiss medical weekly, 150, w20224. https://doi.org/10.4414/smw.2020.20224

OPS. (2015). Organización Panamericana de la Salud Recuperado de: https://www. paho.org/hq/index.php?option=com_content\&view=article\&id=10562:2015-principios-generales-de-higiene-de-los-alimentos-del-codex\&ltemid=41271\&lang=es (accedido el 23/03/2020). 
Pickett, B. E., Sadat, E. L., Zhang, Y., Noronha, J. M., Squires, R. B., Hunt, V., Liu, M., Kumar, S., Zaremba, S., Gu, Z., Zhou, L., Larson, C. N., Dietrich, J., Klem, E. B., \& Scheuermann, R. H. (2012). "ViPR: an open bioinformatics database and analysis resource for virology research". Nucleic acids research, 40, D593-D598.

Plowright, R. K., Parrish, C. R., McCallum, H., Hudson, P. J., Ko, A. I., Graham, A. L., \& Lloyd-Smith, J. O. (2017). Pathways to zoonotic spillover. Nature reviews. Microbiology, 15(8), 502-510. https://doi.org/10.1038/nrmicro.2017.45

Sabbatani, S., \& Fiorino, S. (2009). La peste antonina e il declino dell'Impero Romano. Ruolo della guerra partica e della guerra marcomannica tra il 164 e il 182 d.c. nella diffusione del contagio [The Antonine Plague and the decline of the Roman Empire]. Le infezioni in medicina, 17(4), 261-275

Saunders-Hastings, P. R., \& Krewski, D. (2016). Reviewing the History of Pandemic Influenza: Understanding Patterns of Emergence and Transmission. Pathogens, 5(4), 66. https://doi.org/10.3390/pathogens5040066

Song, W., Gui, M., Wang, X., \& Xiang, Y. (2018). Cryo-EM structure of the SARS coronavirus spike glycoprotein in complex with its host cell receptor ACE2. PLoS pathogens, 14(8), e1007236. https://doi.org/10.1371/journal.ppat.1007236

Tao, Y., Shi, M., Chommanard, C., Queen, K., Zhang, J., Markotter, W., Kuzmin, I. V., Holmes, E. C., \& Tong, S. (2017). Surveillance of Bat Coronaviruses in Kenya Identifies Relatives of Human Coronaviruses NL63 and 229E and Their Recombination History. Journal of virology, 91(5), e01953-16. https://doi.org/10.1128/JVI.0195316

Vijayanand, P., Wilkins, E., \& Woodhead, M. (2004). Severe acute respiratory syndrome (SARS): a review. Clinical medicine, 4(2), 152-160. https://doi.org/10.7861/clinmedicine.4-2-152

Wang, M., Yan, M., Xu, H., Liang, W., Kan, B., Zheng, B., Chen, H., Zheng, H., Xu, Y., Zhang, E., Wang, H., Ye, J., Li, G., Li, M., Cui, Z., Liu, Y. F., Guo, R. T., Liu, X. N., Zhan, L. H., Zhou, D. H., ... Xu, J. (2005). SARS-CoV infection in a restaurant from palm civet. Emerging infectious diseases, 11(12), 1860-1865. https://doi.org/10. 3201/eid1112.041293 
WHO (2020). World Health Organization (CH), Coronavirus disease (COVID-19) outbreak situation Dashboard Recuperado de: https://experience.arcgis.com/experience/685d0ace521648f8a5beeeee1b9125cd (accedido el 04/04/2020).

Worobey, M., Watts, T. D., McKay, R. A., Suchard, M. A., Granade, T., Teuwen, D. E., Koblin, B. A., Heneine, W., Lemey, P., \& Jaffe, H. W. (2016). 1970s and 'Patient 0' HIV-1 genomes illuminate early HIV/AIDS history in North America. Nature, 539(7627), 98-101. https://doi.org/10.1038/nature19827

Woo, P. C., Lau, S. K., Lam, C. S., Lau, C. C., Tsang, A. K., Lau, J. H., Bai, R., Teng, J. L., Tsang, C. C., Wang, M., Zheng, B. J., Chan, K. H., \& Yuen, K. Y. (2012). Discovery of seven novel Mammalian and avian coronaviruses in the genus deltacoronavirus supports bat coronaviruses as the gene source of alphacoronavirus and betacoronavirus and avian coronaviruses as the gene source of gammacoronavirus and deltacoronavirus. Journal of virology, 86(7), 3995-4008. https://doi.org/10.1128/ JVI.06540-11

Wu, Z., \& McGoogan, J. M. (2020). Characteristics of and Important Lessons From the Coronavirus Disease 2019 (COVID-19) Outbreak in China: Summary of a Report of 72314 Cases From the Chinese Center for Disease Control and Prevention. JAMA, 10.1001/jama.2020.2648. Advance online publication. https://doi.org/ 10.1001/jama.2020.2648

Zhou, P., Yang, X. L., Wang, X. G., Hu, B., Zhang, L., Zhang, W., Si, H. R., Zhu, Y., Li, B., Huang, C. L., Chen, H. D., Chen, J., Luo, Y., Guo, H., Jiang, R. D., Liu, M. Q., Chen, Y., Shen, X. R., Wang, X., Zheng, X. S., ... Shi, Z. L. (2020). A pneumonia outbreak associated with a new coronavirus of probable bat origin. Nature, 579(7798), 270-273. https://doi.org/10.1038/s41586-020-2012-7 